\title{
Research on Automotive Castings Foundry Production of Energy Conservation Technology
}

\author{
Wang Zhenfeng ${ }^{a}$, He Xun ${ }^{b}$, Ma Yongjie ${ }^{b}$ \\ a. Mechanical and Electronic Engineering College of Henan Agricultural University, Zhengzhou \\ 450002
}

b. Vocational and Technical College of Shangqiu, Shangqiu 476000

azhenfengking@163.com, ${ }^{\mathrm{b}}$ mayongjie2005@yahoo.com.cn, chexun876@163.com

Keywords: automotive industry, spare parts, casting production; energy conservation technologies

\begin{abstract}
The quality of the casting production has a great influence on the development of automobile industry; auto casting production should be melting, heating systems, exhaust gas comprehensive utilization of waste heat recovery and utilization to promote energy conservation technologies will provide new impetus to the development of the automobile industry.
\end{abstract}

\section{Introductions}

The automotive industry is booming brought tremendous vigor and vitality to our casting production; however, the constraints of the domestic rate of auto parts production of automotive castings become the bottleneck in the development of China's automobile industry. With safety and reliability, energy conservation, lower-cost, comfortable, it is increasing to quality requirements of automotive castings. Casting production of high energy consumption, low energy efficiency, pollution is serious, economic efficiency and poor restricted the development of the foundry industry. Vigorously promote energy conservation technology is an important task for the automotive industry casting production ${ }^{[1]}$.

The automotive castings foundry production, professional cluster assembly line production, casting deep processing can improve the efficiency of the use of production factors of labor, capital, resources and technology, improve the level of equipment and technology, and to expand the scale of production, promote the overall development of China's automotive foundry industry. The casting is a large number of energy-intensive production process, our production 1t qualified energy consumption of iron castings per $500 \sim 700 \mathrm{~kg}$ of coal production $1 \mathrm{t}$ qualified energy consumption of steel castings for $800 \sim 1000 \mathrm{~kg}$ standard coal. Our casting production process and testing methods are not perfect, is one of the important reasons for the high energy consumption ${ }^{[2]}$.

For melting the energy consumption of about $50 \%$ of the entire casting the production of energy. Most of the industrial countries with hot air continuous operation long Cupola melting iron, long-furnace hot air cupola of only a few companies. Most of the cupola furnace only open from 4 to 8 hours to hit, resulting in the loss of furnace heat storage (about melting more than 10\% of energy consumption) and hit the bottom of the furnace coke heat loss. The temperature of hot metal usually is between $1380 \sim 1450^{\circ} \mathrm{C}$. Melting cast steel, the industrialized countries in the smelting alloy steel multi AOD, VOD equipment only a few manufacturers of uses, most still use the electric arc furnace production methods. Sometimes due to the lack of corporate power supply, low electricity at night, you can only open 4-5 heats on shutdown. Open new furnace to increase the time of the furnace heat storage loss. Modeling, core domestic in addition to the minority the backbone enterprises supporting cast for the automotive internal combustion engine using a high density of high-pressure, static pressure, injection pressure, air impact modeling and other advanced and efficient pipeline modeling and resin sand thermal core box, cold box core making process outside most casting companies still use the shock compression molding machine modeling or hand-modeling clay dry sand, sodium silicate sand craft and Tung oil, together grease, clay binder based core-making process, the long production cycle, energy consumption high. Casting Riser large casting overweight extra thick, low casting dimensional accuracy, surface roughness, casting 
rejection rate increased energy consumption, either directly or indirectly ${ }^{[3-5]}$.There are energy conservation technologies and energy conservation measures for automotive castings foundry production.

\section{Smelting-centric energy conservation technologies}

Casting melting part of the energy consumption accounts for production of castings for $50 \%$ of the total energy consumption of the casting scrap melting reasons accounted for about $50 \%$ of the total waste. Therefore, the application of advanced smelting equipment and smelting process is energy conservation measures.

Cast iron smelting energy conservation technologies, for example to illustrate:

(a)Promotion of the use of hot air, water-cooled, continuous operation long Cupola to large-scale, continuous operation for a long time the direction of development is the inevitable trend. Casting enterprises abroad as important energy conservation energy conservation measures to be applied. In recent years, the domestic also done a lot of work and some enterprises have adopted significant energy savings. For example, using the large distance double blast cupola coke, 20\% to 30\% savings reduce rejection rate 5\%, Si and Mn burning were reduced by 5\%, 10\%; lining thin lining cupola water-cooled The long hours of continuous operation, energy savings of $30 \%$ or more; hot air cupola both energy conservation and environmental protection.

(b)promotion cupola --- furnace duplex melting process cupola --- electric furnace duplex melting is the advantage of using cupola preheating, melting, high efficiency and high efficiency induction furnace overheating, and to improve the quality of liquid iron, reach the purpose of reducing energy consumption. In recent years, with increasing coke, pig iron and other raw materials prices rose sharply and casting quality requirements, used alone Furnace growing, the use of the night peak electricity production, have also made good economic and energy conservation effect.

(c)To promote the application of foundry coke cupola melting foundry coke fuel is an effective way to raise the temperature and the quality of liquid iron. Abroad most of the cupola melting was using foundry coke. Foundry Coke or habits and other reasons, since most domestic enterprises are still using metallurgical coke, and even some companies use soil coke, which not only affects the quality of the casting, and coke consumption big price. Such as foundry coke, scrap rate can be reduced to $2 \%$. Therefore, the development of foundry coke production, promotion and application of Foundry Coke improve casting quality; reduce energy consumption, one of the measures.

(d)The cupola oxygen-rich, the dehumidification blast cupola use of metallurgical coke, the temperature of the liquid iron is difficult to stabilize reach $1500{ }^{\circ} \mathrm{C}$, such as the use of $3 \%$ of the oxygen-enriched air supply will be able to guarantee, and net lower energy per ton of liquid iron-consumption $10 \mathrm{Kg}$ around. Cupola the dehumidifying air supply usually humid areas in the south, it can increase the temperature of the molten iron to reduce the burning of silicon, manganese and other elements to improve the quality of liquid iron and melting rate decrease coke consumption $13 \%$ to $17 \%$.

(e)Using computer control technology cupola computer control contains computer ingredients; Burden automatic weighing of quantitative and melting process automation and control. In the optimized state, cupola was available high-quality liquid iron and the right temperature of the liquid iron. Savings of coke from $10 \%$ to $15 \%$ compared with manual control.

(f)To promote the use of cupola dedicated high pressure centrifugal energy saving fan, there are still many cupola Roots, or Yip's volume fan energy consumption big noise. Cupola dedicated high pressure centrifugal energy saving fan, can save $50 \%$ to $60 \%$, and the melting rate of about 33\%.

\section{Heating system at the center of energy conservation technologies}

The energy consumption of industrial furnaces in the foundry production is lower than the melting equipment, approximately $20 \%$ of the total energy consumption. Carry out technological transformation of various furnaces, drying furnace, annealing furnace, should the furnace structure 
to combustion technology. Refractory Materials retrofitting existing furnaces, energy conservation effect is remarkable. Mechanical stokers and coal energy saving than manual about $20 \%$ of the coal-fired industrial furnace stoker, will change the sand, sand core drying furnace coal to fire anti-burn method, coal saving of $15 \%$ to $30 \%$. Far infrared drying technology can save $30 \%$ to $40 \%$ of the core drying furnace. Adoption of large castings the VSR to eliminate stress treatment can handle more than $80 \%$ energy saving compared to thermal aging. Rapid annealing process can malleable iron zinc atmosphere, which can save or reduce coal consumption by more than $50 \%$.

\section{Energy conservation technology to the application of advanced molding and core technology and equipment to improve the quality of castings}

At present, the energy consumption of the domestic several modeling process were "wet, since the hard sand of 1.2 to 1.4, the clay dry sand 3.5 clay dry sand the highest energy consumption, should be eliminated. Lowest energy consumption of the wet type, and adaptable this is one of the wet type is still a large number of reasons. should be based on the quality requirements of castings, castings characteristics to selection of state-of-the-art high-pressure, static pressure, injection pressure, air impact modeling technology and equipment, as well as the application from the hard sand, lost foam casting technology and special casting techniques with resin from the hard sand, water glass organic esters since molding and core process hard sand and VRH law instead of dry clay and to improve casting dimensional accuracy and reduce the surface roughness, improve casting quality, reduce energy consumption special casting process compared with ordinary clay sand casting dimensional accuracy of 2 to 4 , a small surface roughness of 1 to 3 , to reduce $10 \%$ to $30 \%$ mass, and allowance reduced by $5 \%$ or more, the casting scrap rate also greatly reduces the comprehensive energy conservation effect significantly. The castings pass rate increased by $1 \%, 8 \sim$ $10 \mathrm{Kg}$ production per ton of hot metal castings, the equivalent of saving coal $\sim 7 \mathrm{Kg}$ casting scrap rate for every $1 \%$ reduction in energy consumption is reduced by $1.25 \%$, casting quality every $1 \%$ reduction on a $1.01 \%$ reduction in energy consumption can be seen, the use of advanced technology and equipment, improve casting quality, reduce casting scrap rate is to improve energy efficiency, and an important way to reduce energy consumption.

\section{Promotions of low-stress iron castings, cast ductile iron castings, ductile iron riser casting and steel heat subsidies for energy conservation technology}

In china, per ton of castings energy consumption for gray iron castings heat aging for $40 \sim 100$ $\mathrm{Kg}$ of standard coal for Ductile Iron Castings annealing, normalizing the energy consumption per ton of castings for $100 \sim 180 \mathrm{Kg}$ of standard coal. In addition to the small number of enterprises producing automotive engine, internal combustion engine castings without thermal aging process, most of the production of such castings enterprises still use thermal aging process to eliminate stress, which is one of the reasons of the high energy consumption of China's foundry industry. To promote the use of thin-walled high-strength gray iron casting production technology and high-silicon carbon iron castings production technology, production of automotive engine, internal combustion engine block, cylinder head and the machine bed castings, iron castings available without thermal aging process low-stress, to save energy.

In China, Ferritic Ductile Iron of high toughness and high strength Pearlite Ductile Iron castings account for a large proportion, usually annealing, normalizing. Cast ductile iron production technology eliminates the need for annealing, normalizing processes for energy conservation, to avoid casting deformation due to the high temperature treatment, oxidation defects. Ductile iron Riser less casting process, process yield can be increased by $10 \%$ to $30 \%$, reducing energy consumption is also very significant. For example, in 2003, casting output of 19.87 million tons, of which 10,490,000 tons gray iron castings, ductile iron castings for the 4.7 million tons, therefore, to promote the use of low-stress iron castings, ductile iron castings and ductile iron cast Riser less casting technology, has important implications for the industry-wide energy saving. The steel castings riser insulation subsidies can make the process produced from $60 \%$ to $80 \%$. 


\section{Promote the cupola exhaust comprehensive utilization and the heat recovery technology to achieve cleaner production and energy efficiency}

90\% of our cast iron cupola smelting production, this situation will remain for a long time. Waste heat utilization of the foundry industry is mainly concentrated in the cupola. Cupola melting emits large amounts of flue gas, flue gas containing the combustible carbon particles and combustible gas, not only cause environmental pollution, and waste a lot of heat. Cupola melting, except $38 \% \sim 43 \%$ of the effective heat for smelting, the heat taken away by the flue gas of $7 \%$ to $16 \%$, incomplete combustion of the heat (the combustible gas) is $20 \%$ to $25 \%$, the solid is not completely The combustion heat of $3 \%$ to 5\%. These heat accounts for $30 \%$ to $45 \%$. This shows that the great the cupola melting the potential for waste heat utilization. The vast majority of China's cupola waste heat utilization dense tendons furnace gall preheated blast hot air temperature is about $200{ }^{\circ} \mathrm{C}$, waste heat utilization is low. In recent years, some enterprises use a long furnace continuous operation hot air cupola, to make full use of exhaust heat and burning carbon particles and combustible gas burning heat, hot air temperature of 600 to $800{ }^{\circ} \mathrm{C}$ cupola furnace hot metal temperature of $1500 \sim 1550{ }^{\circ} \mathrm{C}$, melting efficiency of $45 \%$, both to achieve energy conservation, improve the quality of molten iron of purpose, but also to achieve the requirements of environmental protection.

\section{Conclusions}

Casting the production of energy conservation, improve casting should be based on quality, technical level as the core content, integrated advanced smelting technology and equipment of advanced modeling, computer technology, soot treatment and waste utilization, the formation of the composite technology of casting production reduce the castings production costs, and achieve substantial energy saving in the production process of casting, and lay the foundation for the sustainable development of the foundry industry. Through the above analysis, can provide a number of energy conservation technologies and measures for the production of China's foundry industry, but also hope that these technologies and measures will enable the foundry industry out of the woods.

\section{References}

[1]MA Yong-jie. Energy conservation Technology and Energy conservation Measures in Casting Production [J].HOT WORKING TECHONOLOGY, 2008, 37(11):107-110.

[2]LIU Dong-mei, ZHANG Feng-wen, HE Li-ming. Measurement on Energy Conservation and Emissions Reduction of Cast Iron Production [J]. FOUNDRY, 2011, 60(7):693-696.

[3]Zhang Boming. A Correct Understanding of the Energy Consumption Casting [J]. Modern Cast Iron, 2011, 31(1):94-95.

[4]LI Yuan-yuan, CHEN Wei-ping, HUANG Dan, Atl. Energy Conservation and Emissions Reduction and Strategy Involved in Foundry Industry. FOUNDRY, 2011, 59(11):1141-1147.

[5]QI Xiao-bing, Tang Ji, LIU Zi-an, Atl. A Copper Alloy Mold Casting Producing Line for Ductile iron Castings Used in Automobile. FOUNDRY, 2001, 50(10):629-631. 